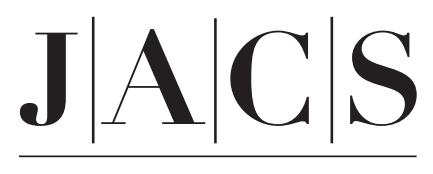

A R T I C L E S

Published on Web 03/15/2003

\title{
A Priori Assessment of the Stereoelectronic Profile of Phosphines and Phosphites
}

\author{
Katharine D. Cooney, ${ }^{\dagger}$ Thomas R. Cundari, ${ }^{* \neq}$ Norris W. Hoffman, $§$ Karl A. Pittard," \\ M. Danielle Temple, ${ }^{\perp}$ and Yong Zhao\# \\ Contribution from the Department of Chemistry, University of Memphis, \\ Memphis, Tennessee 38152 and Department of Chemistry, The University of South Alabama,
} Mobile, Alabama 36688

Received October 7, 2002

\begin{abstract}
This research has demonstrated the utility of a rigorously calibrated, molecular mechanics/ semiempirical quantum mechanical protocol for developing stereoelectronic (Tolman) maps for phosphine ligands. A computational analysis of alkyl and aryl phosphines in common usage suggests that these ligands are quite similar stereoelectronically. A noticeable gap in the Tolman map for common phosphines is observed for large, electron-poor phosphines. Several candidates meeting these criteria were identified, the most promising of which is $\mathrm{P}\left(t-\mathrm{C}_{4} \mathrm{~F}_{9}\right)_{3}$. Phosphines in which the phosphorus participates in a ring, which comprise a very small subset of reported phosphines, have very interesting stereoelectronic properties, particularly those in which the ligating phosphorus is part of a three-membered ring. In terms of steric properties, the symmetric deformation coordinate proposed by Orpen and co-workers on the basis of crystallographic studies is calculated with sufficient accuracy using PM3(tm) to allow good confidence in predictions of novel phosphines. For quantification of the electronic properties of phosphines, we analyzed changes in the $\mathrm{CO}$ stretching frequency upon changing the ancillary phosphine ligands.
\end{abstract}

\section{Introduction}

The de novo design of homogeneous catalysts with specific regio- and stereospecificity is an ultimate, albeit elusive, goal of computational organometallic (OM) chemistry. From a computational perspective, OMs incorporate the formidable challenges of both organic and metallic compounds. ${ }^{1}$ For the former, the bonding descriptions can usually be treated with very fast, approximate methods such as molecular mechanics $(\mathrm{MM})^{2}$ and semiempirical quantum mechanics (SEQM). ${ }^{3}$ The challenge in dealing with organic species often concerns their very large size and conformational complexity. This is also expected to be an issue for the large, bulky ligands used in OMs to engender some degree of thermodynamic and kinetic stability or to produce favorable stereochemical/regiochemical outcomes. For the "core"-the metal and its inner coordination sphere-of organotransition metal species, computational challenges include large numbers of electrons and orbitals, electron correlation, and relativistic effects.

\footnotetext{
* Address correspondence to this author at UNT.

Present address: Carroll College, Helena, MT 59625.

$\div$ Present address: Department of Chemistry, University of North Texas, Box 305070, Denton, TX 76203-5070.

${ }^{\perp}$ Present address: Lyon College, Batesville, AR 72501.

" Present address: North Carolina State University, Raleigh, NC 27695.

$\S$ University of South Alabama.

\# University of Memphis.

(1) Computational Organometallic Chemistry; Cundari, T. R., Ed.; MarcelDekker: New York, 2001

(2) See: Norrby, P. O. In ref 1, pp 7-37, for a discussion of the development of molecular mechanics force fields for organometallics.

(3) Semiempirical Quantum Mechanics. Zerner. Reviews in Computational Chemistry; Boyd, D. B., Lipkowitz, K. B., Eds.; 1991; Vol. 2, p 313.
}

4318 - J. AM. CHEM. SOC. 2003, 125, 4318-4324
A brief inspection of the literature is sufficient to detail the recent, enormous progress in computational $\mathrm{OM}$ chemistry. ${ }^{1}$ Notable milestones include hybrid quantum mechanics-molecular mechanics (QM/MM), density functional theory (DFT), and effective core potentials (ECPs). These theoretical improvements, combined with advances in computer hardware and software, allow one to seriously consider the proposition of rational, de novo design of $\mathrm{OM}$ catalysts.

Phosphines $\left(\mathrm{PR}_{3}, \mathrm{R}=\right.$ alkyl, aryl, alkoxy, etc.) comprise perhaps the most important class of co-ligands in homogeneous catalysis. ${ }^{4}$ Since the seminal work of Tolman, ${ }^{5}$ it has been appreciated that the steric profile of the phosphine can impart a significant degree of control over the outcome of transition metal-mediated reactions. ${ }^{6}$ The steric profile was originally enumerated by the simple, yet ingenious, calculation of the phosphine cone angle derived from space-filling models. Subsequently, researchers have focused on implementing different enumeration schemes to quantify steric bulk ${ }^{6,7}$ and extending the cone angle concept to other ligand types. ${ }^{8}$

Research has also focused on evaluation of the electronic profile of phosphines in organometallic catalysis. Tolman's landmark Chemical Reviews article ${ }^{5}$ discusses the use of the

(4) Crabtree, R. H. The Organometallic Chemistry of the Transition Metals, 3rd ed.; Wiley: New York, 2000.

(5) Tolman, C. A. Chem. Rev. 1977, 77, 313

(6) White, D. P. In ref 1 , pp 39-67.

(7) (a) Immirzi, A.; Musco, A. Inorg. Chim. Acta 1977, 25, L41. (b) White D. P.; Taverner, D. B.; Leach, P. G. L.; Coville, N. J. J. Comput. Chem 1993, 14, 1042 .

(8) See, for example: Choi, M.-G.; White, D. P.; Brown, T. L. Inorg. Chem 1994, 33, 5591. Also see: Caffery, M. L.; Brown, T. L. Inorg. Chem. 1991 30,3907 . 
Scheme 1

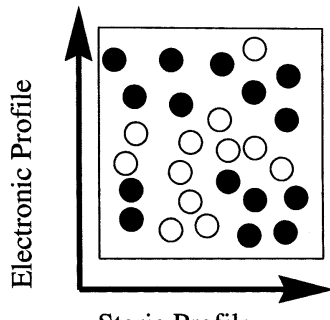

Steric Profile

carbonyl stretching frequencies, assuming such a functionality is present, as an electronic parameter for phosphines. Much of the analysis is couched in terms of $\mathrm{PR}_{3}$ and $\mathrm{CO}$ as $\sigma$ donors and as $\pi$ acids, although considerable discussion remains as to the nature of the orbitals responsible for phosphine back-bonding interactions. ${ }^{9}$ Giering and co-workers have extensively discussed the QALE (quantitative analysis of ligand effects) scheme for probing the electronic profile of phosphine and other ligands. ${ }^{10}$ Lever et al. used redox couples to quantify ligand electronic parameters. ${ }^{11}$ Crabtree et al. reported a scheme for quantifying the electronic impact of different phosphines using ab initio calculations on $\mathrm{Ni}(\mathrm{CO})_{3}\left(\mathrm{PR}_{3}\right)$ complexes. ${ }^{12}$ Koga et al. ${ }^{13}$ focused on $\mathrm{PR}_{3}$ ligands in order to develop metal-independent measures of electronic character. Pittard and co-workers used PM3(tm) quantum mechanics to evaluate semiempirical electronic parameters (SEP) for phosphines ligated to $\mathrm{Mo}(\mathrm{CO})_{5}\left(\mathrm{PR}_{3}\right)$, $\mathrm{W}(\mathrm{CO})_{5}\left(\mathrm{PR}_{3}\right)$, and $\mathrm{CpRh}(\mathrm{CO})\left(\mathrm{PR}_{3}\right) .{ }^{14}$ The calculated SEP were found to be fairly independent of the metal fragments.

In combinatorial design, it is of obvious utility to quickly and reliably compute the stereoelectronic characteristics of a ligand before going to the time and expense of attempting the synthesis of both the ligand and its OM complexes. In terms of a simple two-dimensional plot, Scheme 1, the catalyst designer seeks to achieve the maximum degree of chemical diversity with the minimum number of ligands. To this end, duplication is to be avoided, but so are "gaps" (open circles, Scheme 1) in chemical space.

This paper reports a study of rhodium Vaska complexes, trans- $\mathrm{Rh}\left(\mathrm{PR}_{3}\right)_{2}(\mathrm{CO}) \mathrm{X}$, where $\mathrm{R}$ includes hydrocarbyl moieties and $\mathrm{X}$ is a uninegative ligand such as a halide, acetate, isocyanate, etc. These complexes are chosen given the large number of examples that have been structurally characterized. Additionally, the square-planar Rh(I) motif is an important one in catalysis, e.g., hydroformylation and asymmetric hydrogenation. $^{4}$

\section{Computational Methods}

Calculations reported herein utilized the PM3(tm) semiempirical Hamiltonian ${ }^{15}$ contained within the Spartan ${ }^{16}$ and $\operatorname{Titan}^{17}$ programs. All

(9) Dunne, B. J.; Morris, R. B.; Orpen, A. G. J. Chem. Soc., Dalton Trans. 1991, 653.

(10) Wilson, M. R.; Prock, A.; Giering, W. P.; Fernandez, A. L.; Haar, C. M.; Nolan, S. P.; Foxman, B. M. Organometallics 2002, 21, 2758, and references therein

(11) (a) Lever, A. B. P. Inorg. Chem. 1990, 29, 1271. (b) Lever, A. B. P. Inorg. Chem. 1991, 30, 1980.

(12) Perrin, L.; Clot, E.; Eisenstein, O.; Loch, J.; Crabtree, R. H. Inorg. Chem. 2001, 40, 5806

(13) Suresh, C. H.; Koga, N. Inorg. Chem. 2002, 41, 1573.

(14) Gillespie, A. M.; Pittard, K. A.; Cundari, T. R.; White, D. P. Internet Electron. J. Mol. Des. 2002, 1, 242.

(15) (a) Hehre, W. J.; Yu, J. Semiempirical Models for Transition Metals. Book of Abstracts, 210th ACS National Meeting, Chicago, IL, Aug 1995; pp 20-24. (b) Hehre, W. J.; Yu, J. Semiempirical Molecular Orbital Models for Transition Metal Inorganics and Organometallics. Book of Abstracts, 211th ACS National Meeting; New Orleans, LA, March 24-28, 1996.
Scheme 2

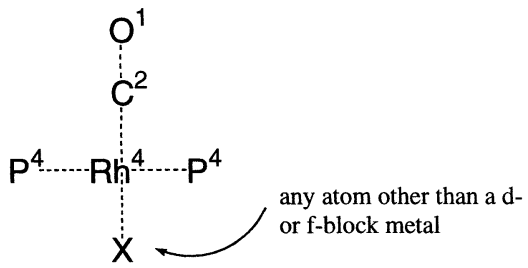

calculations employed the default PM3 (for main group elements) and PM3(tm) (for Rh) parameters. The suitability of the PM3(tm) Hamiltonian for Rh-Vaska complexes is discussed in detail in Section 1, and for other TM complexes elsewhere. ${ }^{18,19}$

Conformational searching was done using a hybrid Monte Carlo method and the Merck Molecular Force Field (MMFF9420) with the MOE program. ${ }^{21}$ The molecular dynamics simulations were run at 300 $\mathrm{K}$ with a time step of $5 \mathrm{fs}$. After an equilibration period of $5 \mathrm{ps}$, geometry "snapshots" were collected every $0.5 \mathrm{ps}$ with a total simulation time of $1 \mathrm{~ns}$. These 2000 conformations were then geometry optimized using MMFF94. From these 2000 minimized geometries, the lowest energy structure was extracted and submitted to PM3(tm) geometry optimization and frequency calculation, whereupon $\mathrm{S}_{4}{ }^{\prime}$ and the $\mathrm{CO}$ stretching frequency were obtained.

\section{Crystallographic Database Searching}

A search of the Cambridge Structural Database ${ }^{22}$ was performed for monometallic, Rh-Vaska complexes with the motif in Scheme 2 (superscripted numbers refer to the atom coordination number). Complexes with chelating phosphines were deleted, as were duplicate structures. Refinements are employed to ensure the search focused on the most reliable crystal structures: INSIST-ON-COORDS (search only systems in which fractional atomic coordinates are deposited), INSISTNO-DISORDER (search systems with no crystallographic disorder), INSIST-PERFECT-MATCH (search entries with completely matched chemical and crystallographic connectivities), INSIST-ERROR-FREE (include only entries whose published bond lengths agree with the recalculated values to within $0.05 \AA$ ), and INSIST-NO-POLYMERS (exclude entries with polymeric bonds in the crystal connectivity).

For each CSD "hit" the following metric parameters were tabulated: RhP, RhC, CO, and RhX bond lengths, PRhP, XRhP, $\mathrm{CRhP}$, and $\mathrm{CRhX}$ bond angles. For metrics involving the phosphorus atoms, the two individual bond length (angle) values were averaged, although in practice the $\mathrm{Rh}$ coordination spheres were of local $C_{s}$ symmetry given the trans arrangement of the phosphine ligands. Statistical outliers (i.e., those structures with values lying more than \pm 4 standard deviations from mean values

(16) Spartan; Wavefunction, Inc.: 18401 von Karman Ave., Suite 370, Irvine, CA 92612.

(17) Titan; Schrödinger Inc.: 1500 S. W. First Ave., Suite 1180, Portland, OR, 97201-5815 (http://www.schrodinger.com/Products/titan.html).

(18) (a) Cundari, T. R.; Deng J. J. Chem. Info. Comput. Sci. 1999, 39, 376. (b) Donovan-Merkert, B. T.; Clontz, C. R.; Rhinehart, L. M.; Tijong, H. I.; Carlin, C. M.; Cundari, T. R.; Rheingold, A. L.; Guzei, I. Organometallics 1998, 17, 1716. (c) Cao, M.; Liem, V.; Hoffman, N. W.; Kwan, M. L.; Little, J. K.; McGilvray, J. M.; Morris, C. B.; Soderberg, B. C.; Wierzbicki, A.; Cundari, T. R.; Lake, C. M.; Valente, E. A. Organometallics 2001, 20 , 2270 .

(19) (a) Adam, K. R.; Atkinson, I. M.; Lindoy, L. F. J. Mol. Struct. 1996, 384 183. (b) Borve, K.; Jensen, V. R.; Karlsen, T.; Stoveng, J. A.; Swang, O. J. Mol. Model. 1997, 3, 193. (c) Decker, S. A.; Klobukowski, M. Can. J. Chem. 1999, 77, 65. (d) Decker, S. A.; Donini, O.; Klobukowski, M. J. Phys. Chem. A 1997, 101, 8734.

(20) Halgren, T. A. J. Comput. Chem. 1996, 17, 490.

(21) MOE, Molecular Operating Environment, Chemical Computing Group, Inc., 1255 University St., Suite 160, Montreal, Quebec, Canada, H3B 3X3.

(22) Allen, F. H.; Kennard, O. Chem. Des. Autom. News 1993, 8, 31 
of the bond lengths and angles) were manually removed from analysis in order to eliminate structures with unresolved disorder and other errors.

\section{Results and Discussion}

\section{Validation of PM3(tm) for Rh-Vaska Complexes.}

Previous research from our group and others has concentrated on the reliability of the PM3(tm) method for rapid structural prediction of large OM complexes. ${ }^{18,19}$ A systematic survey in 1998 for the 19 transition metals then parametrized indicated that the predictive ability of PM3(tm) generally improved for TM complexes of the heavier (2nd and 3rd transition series) metals, and for organometallics in comparison to Werner-type complexes, particularly examples of the latter with neutral Lewis base ligands such as water. ${ }^{18 a}$ Earlier theory-experiment studies used PM3(tm) to assist in interpretation of Rh-cyclopentadienyl ${ }^{18 \mathrm{~b}}$ and $\mathrm{CpRu}$ chemistry. ${ }^{18 \mathrm{c}}$ However, our experience suggests that significant caution must be used in attaching undue, quantitative significance to PM3(tm)-derived energies, particularly when comparing widely disparate (in terms of the metal spin and oxidation states, as well as ligating atom and bond types) chemical entities.

In light of the high degree of similarity among the Rh-Vaska target complexes, the PM3(tm) semiempirical methodology was chosen, as it constitutes the only viable option for the rapid (typically within several hours on a single-processor, UNIX workstation or high-end PC) geometry optimization of a large number of sizable ( $\approx 50-100$ atoms) OMs.

To probe the performance envelope of PM3(tm) for Rh-Vaska complexes, an extensive comparison of calculated versus experimental (X-ray crystallography) geometries was performed. A search of the Cambridge Structural Database (CSD) using the search criteria described above (Scheme 2) yielded $41 \mathrm{Rh}$ Vaska complexes. PM3(tm) geometry optimizations were carried out starting from the X-ray coordinates. Of the 41 structures, PM3(tm) was able to converge to a plausible geometry in 36 of $41(88 \%)$ cases. Inspection of the data for the remaining five rogue complexes indicates that the major difficulty for modeling $\mathrm{Rh}$-Vaska complexes with PM3(tm) lies in those complexes that possess carbon-based X groups, e.g., methyl and phenyl. In such cases an exaggerated $\mathrm{Rh} \cdot \cdots \mathrm{H}-\mathrm{C}$ agostic interaction was the culprit. $^{23}$

Apart from the recalcitrant Rh-Vaska complexes containing carbon-based $\mathrm{X}$ groups, the results obtained using PM3(tm), insofar as geometric prediction is concerned, are excellent. Average values for the Rh-Vaska complexes are as follows (sample standard deviations in the last significant figure are given in parentheses):

(23) Hybrid quantum mechanics/molecular mechanics (UFF force field ${ }^{23 a}$ for phosphine substituents, and the B3LYP functional ${ }^{23 \mathrm{~b}}$ and Stevens effective core potentials and valence basis sets ${ }^{23 c}$ for the remaining atoms) on three of the five rogue structures showed good agreement between the computed and experimental geometries, supporting the conclusion that the difficulties encountered for complexes of these type are due to deficiencies in the $\mathrm{PM} 3(\mathrm{tm})$. The complexes chosen, trans $-\mathrm{Rh}(\mathrm{PPh} 3) 2(\mathrm{CO})(-\mathrm{C} \equiv \mathrm{CPh}),{ }^{23 \mathrm{~d}}$ trans-Rh(PMe3)2(CO)(Ph), ${ }^{23 \mathrm{e}}$ and trans-Rh(PMe3)2(CO)(Me), ${ }^{23 \mathrm{e}}$ possess a sp, $\mathrm{sp}^{2}$, and $\mathrm{sp}^{3}$ hybridized carbon-based $\mathrm{X}$ group, respectively. (a) Rappe, A. K.; Casewit, C. J.; Colwell, K. S.; Goddard, W. A.; Skiff, W. M. J. Am. Chem. Soc. 1992, 114, 10024. (b) Becke, A. D. J. Chem. Phys. 1993, 98 5648. (c) Stevens, W. J.; Krauss, M.; Basch, H.; Jasien, P. G. Can. J. Chem. 1992, 70, 612. (d) Choi, J. C.; Osakada, K.; Yamamoto, T. Organometallics 1998, 17, 3044. (e) Boyd, S. E.; Field, L. D.; Hambley, T. W.; Partridge, M. G. Organometallics 1993, 12, 1720.
$\mathrm{RhP}=2.33(3) \AA$, exptl; 2.34(2) ̊, PM3;

$\mathrm{RhC}=1.81(3) \AA$, exptl; 1.86(5) $\AA$, PM3;

$\mathrm{CO}=1.15(2) \AA$, exptl; $1.15(1) \AA$, PM3;

$\mathrm{PRhP}=173(5)^{\circ}$, exptl; 170(9) ${ }^{\circ}, \mathrm{PM} 3$;

$\mathrm{CRhP}=91(2)^{\circ}$, exptl; 91(2) $)^{\circ}$ PM3;

$\mathrm{XRhC}=176(4)^{\circ}$, exptl; 175(5) ${ }^{\circ}, \mathrm{PM} 3$;

$\mathrm{XRhP}=90(3)^{\circ}$, exptl; 90(3) ${ }^{\circ}, \mathrm{PM} 3$.

Closer inspection indicates that for bond lengths the largest errors are, not surprisingly, for the $\mathrm{RhC}$ (carbonyl) bond length, which tends to be systematically too long at the PM3(tm) level. The average error is $0.05 \AA(<35)$ for predicted $\mathrm{Rh}$-carbonyl bond length, while all other bond lengths agree to within 0.02 $\AA$ of experiment on average. For the ligand-metal-ligand bond angles, the most difficult angle to describe is the $\mathrm{P}-\mathrm{Rh}-\mathrm{P}$ angle, which tends to be systematically low with PM3(tm). The average difference between theory and experiment is $3^{\circ}$ for $\mathrm{P}-\mathrm{Rh}-\mathrm{P}$. Hence, in general the PM3 (tm) model provides excellent metric prediction at a very reasonable computational cost.

For all metrics, across the entire large Rh-Vaska dataset, computations and experiment agree to within one standard deviation. This agreement for an assortment of $\mathrm{X}$ groups, carbon-based systems not withstanding, and phosphine ligands is competitive with high-level ab initio methods ${ }^{24}$ in only a fraction of the computational time. The longest of the PM3(tm) geometry optimizations took only $13 \mathrm{~h}$ on a single-processor workstation; on average full PM3(tm) geometry optimization required less than $3 \mathrm{~h}$ per Rh-Vaska complex.

On the basis of the results of this extensive calibration visà-vis examples reported in the Cambridge database, the PM3(tm) semiempirical Hamiltonian seems a reliable tool for structural prediction of large, experimentally relevant $\mathrm{Rh}$-Vaska complexes. Below, we apply this methodology to novel examples.

2. Assessment of the Steric Profile of Phosphines. A variety of metrics of varying degrees of complexity have been described for phosphines and other popular transition metal ligation, most notably the cone angle $(\theta),{ }^{5}$ and the ligand repulsive energy $\left(E_{\mathrm{R}}\right){ }^{25}$ Boeyens et al. have recently reported the use of X-ray crystallographic information for assessing the steric size of phosphites. ${ }^{26}$ Orpen et al. ${ }^{9}$ have utilized the angles at the coordinated phosphine $\mathrm{P}$ for the same purposes, defining the symmetric deformation coordinate $\left(\mathrm{S}_{4}{ }^{\prime}\right)$ thus,

$$
\mathrm{S}_{4}{ }^{\prime}=\alpha_{1}+\alpha_{2}+\alpha_{3}-\beta_{1}-\beta_{2}-\beta_{3}
$$

The deformation coordinate is employed as the steric measure for the present research. The ease of determining $\mathrm{S}_{4}{ }^{\prime}$ from both $\mathrm{X}$-ray crystallography databases and computational chemistrybased geometry optimizations is a major factor in favor of the use of the symmetric deformation coordinate as a measure of steric bulk. As the phosphine steric bulk increases, $\mathrm{S}_{4}{ }^{\prime}$ decreases (Scheme 3).

Sophisticated steric metrics have been proposed to take into account the fact that ligands are flexible entities whose size can change in response to the transition metal complex of which it is a component. Previous research has shown $\mathrm{S}_{4}{ }^{\prime}$ for a phosphine

(24) (a) Cundari, T. R.; Gordon, M. S. Coord. Chem. Rev. 1996, 147, 87. (b) Benson, M. T.; Cundari, T. R.; Lutz, M. L.; Sommerer, S. O. Reviews in Computational Chemistry; Boyd, D. B., Lipkowitz, K. B., Eds.; 1996; Vol. 8, p 145.

(25) Brown, T. L. Inorg. Chem. 1992, 31, 1286

(26) Smith, J. M.; Coville, N. J.; Cook, L. M.; Boeyens, J. C. A. Organometallics $\mathbf{2 0 0 0}, 19,5273$ 
Scheme 3

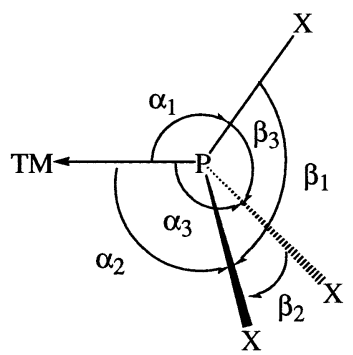

Table 1. Symmetric Deformation Coordinate $\left(\mathrm{S}_{4}{ }^{\prime}\right)$ for Phosphines ${ }^{a}$

\begin{tabular}{lrrrrrr}
\hline & $x$ (AGO) & $\sigma$ (AGO) & $n$ (AGO) & $x$ (TRC) & $\sigma$ (TRC) & $n$ (TRC) \\
\hline $\mathrm{Me}$ & 47 & 12 & 879 & 46 & 10 & 1676 \\
$\mathrm{PhMe} 2$ & 39 & 10 & 494 & 39 & 9 & 1161 \\
${ }^{n} \mathrm{Pr}$ & 24 & 9 & 10 & 30 & 10 & 61 \\
$\mathrm{C}_{2} \mathrm{H}_{4} \mathrm{CN}$ & 31 & 8 & 6 & 31 & 10 & 14 \\
$\mathrm{Et}$ & 33 & 11 & 367 & 35 & 9 & 957 \\
${ }^{n} \mathrm{Bu}$ & 28 & 12 & 32 & 31 & 9 & 128 \\
$\mathrm{Ph}_{2} \mathrm{Me}$ & 34 & 11 & 255 & 38 & 9 & 339 \\
$\mathrm{CF}_{3}$ & 76 & & 1 & 67 & 8 & 3 \\
$\mathrm{Ph}$ & 28 & 12 & & & & \\
$p$-tol & 34 & 5 & 17 & 33 & 6 & 62 \\
${ }^{i} \mathrm{Pr}$ & 26 & 9 & 58 & 28 & 7 & 369 \\
$\mathrm{Bz}$ & 27 & 6 & 6 & 34 & 8 & 18 \\
$\mathrm{Cy}$ & 18 & 11 & 88 & 22 & 8 & 270 \\
${ }^{t} \mathrm{Bu}$ & 3 & 11 & 23 & 10 & 9 & 39 \\
$o$-tol & 15 & 9 & 6 & 27 & 9 & 33 \\
$\mathrm{Mes}$ & -18 & 8 & 3 & -17 & 4 & 22 \\
\hline
\end{tabular}

${ }^{a} x=$ sample mean for $\mathrm{S}_{4}{ }^{\prime}(\mathrm{deg}), \sigma=$ sample standard deviation for $\mathrm{S}_{4}{ }^{\prime}$ (deg), $n=$ number of samples; AGO data reported by Orpen; ${ }^{9}$ TRC data obtained for the present research.

to be sensitive to the chemical environment of the complex in which it is found. ${ }^{9}$ Hence, not only can $\mathrm{S}_{4}{ }^{\prime}$ be useful for quantifying the steric bulk of a phosphine ligand, but assessment of $\mathrm{S}_{4}{ }^{\prime}$ for a particular phosphine with different metal complexes could possibly yield insight into the steric profile of the latter.

In 1991 Orpen tabulated $\mathrm{S}_{4}{ }^{\prime}$ values for common phosphines using X-ray crystallographic data. ${ }^{9}$ Given the rapid growth of the Cambridge Structural Database (CSD) to the point where it now contains over 250000 experimental structures, roughly half of which are transition metal complexes, it was decided to reevaluate $\mathrm{S}_{4}{ }^{\prime}$. One important difference is that in the present work we limited our search to transition metal complexes. Orpen utilized both metal and nonmetal phosphine complexes (e.g., phosphine oxides).

Table 1 contains a comparison of the obtained $\mathrm{S}_{4}{ }^{\prime}$ values, the sample standard deviation in $\mathrm{S}_{4}{ }^{\prime}$, and the number of samples for transition metal phosphine complexes. Orpen's data are repeated for comparison, and a plot of the present and previous $\mathrm{S}_{4}{ }^{\prime}$ values are given in Figure 1. Almost without exception, the present transition metal phosphines $\mathrm{S}_{4}{ }^{\prime}$ are commensurate with those determined by Orpen, ${ }^{9}$ the largest difference being for $\mathrm{P}(o \text {-tolyl })_{3}$, which was determined to be $15 \pm 9^{\circ}$ (6 samples) by Orpen in 1991 and $27 \pm 9^{\circ}$ (33 samples) in the present research, for which many more examples are now available. The extremely large number of $\mathrm{PPh}_{3}$ examples $(>10000$ samples) defeated all our statistical software, and so given the close correspondence between the present and previous $\mathrm{S}_{4}{ }^{\prime}$, we will use Orpen's value of $\mathrm{S}_{4}{ }^{\prime}=28(12)^{\circ}$.

The symmetric deformation coordinate was calculated for a series of Rh-Vaska complexes, viz., trans- $\mathrm{Rh}\left(\mathrm{PR}_{3}\right)_{2}(\mathrm{CO}) \mathrm{Cl}$, where $\mathrm{PR}_{3}$ are the phosphines in Table 1. A molecular-

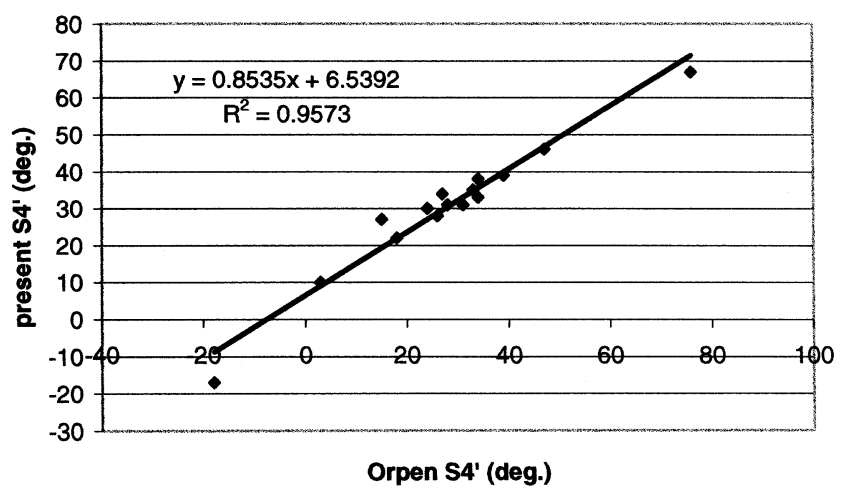

Figure 1. Comparison of symmetric deformation coordinate $\left(\mathrm{S}_{4}{ }^{\prime}\right)$ obtained from X-ray crystallographic data from present research, for transition metal phosphine complexes, and that reported in 1991 by Orpen. ${ }^{9}$ Data from Table 1.

Table 2. $\mathrm{PM} 3(\mathrm{tm})$-Calculated Symmetric Deformation Coordinates $\left(\mathrm{S}_{4}{ }^{\prime}\right)$ for Phosphine Ligands in Rh-Vaska Complexes ${ }^{a}$

\begin{tabular}{lrrrcc}
\hline & $x($ deg $)$ & $\sigma($ deg $)$ & $n($ deg $)$ & ${\mathrm{PM} 3(\mathrm{tm}) \mathrm{S}_{4}{ }^{\prime}}$ & $\mathrm{PM} 3(\mathrm{tm}) \mathrm{SEP}$ \\
\hline $\mathrm{Me}$ & 46 & 10 & 1676 & 52 & 2102 \\
$\mathrm{PhMe}$ & 39 & 9 & 1161 & 47 & 2108 \\
${ }^{n} \mathrm{Pr}$ & 30 & 10 & 61 & 34 & 2108 \\
$\mathrm{C}_{2} \mathrm{H}_{4} \mathrm{CN}$ & 31 & 10 & 14 & 45 & 2140 \\
$\mathrm{Et}$ & 35 & 9 & 957 & 35 & 2105 \\
${ }^{n} \mathrm{Bu}$ & 31 & 9 & 128 & 35 & 2106 \\
$\mathrm{Ph}{ }_{2} \mathrm{Me}$ & 38 & 9 & 339 & 41 & 2121 \\
$\mathrm{CF}_{3}$ & 67 & 8 & 3 & 60 & 2198 \\
$\mathrm{Ph}$ & 28 & 12 & & 35 & 2123 \\
$p$-tol & 33 & 6 & 62 & 35 & 2122 \\
${ }^{i} \mathrm{Pr}$ & 28 & 7 & 369 & 35 & 2096 \\
$\mathrm{Bz}$ & 34 & 8 & 18 & 40 & 2120 \\
$\mathrm{Cy}$ & 22 & 8 & 270 & 21 & 2104 \\
${ }^{t} \mathrm{Bu}$ & 10 & 9 & 39 & 17 & 2084 \\
$o$-tol & 27 & 9 & 33 & 39 & 2124 \\
$\mathrm{Mes}$ & -17 & 4 & 22 & 31 & 2129 \\
\hline
\end{tabular}

${ }^{a} x=$ sample mean for $\mathrm{S}_{4}{ }^{\prime}(\mathrm{deg}), \sigma=$ sample standard deviation for $\mathrm{S}_{4}{ }^{\prime}$ (deg), $n=$ number of samples.

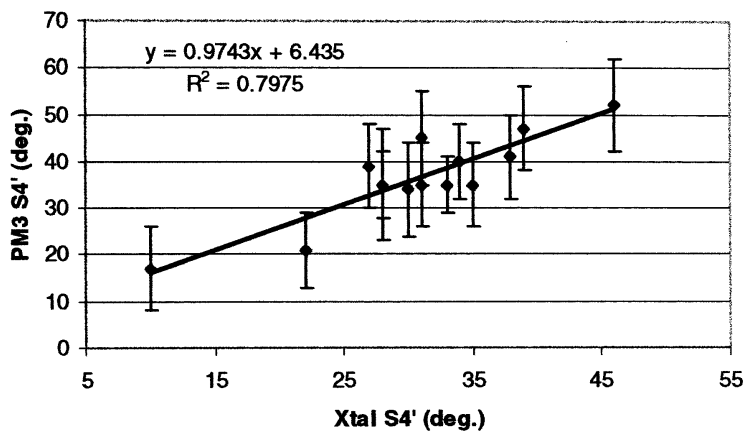

Figure 2. Comparison of $\mathrm{PM} 3(\mathrm{tm})$-calculated symmetric deformation coordinate $\left(\mathrm{S}_{4}{ }^{\prime}\right)$ of $\mathrm{PR}_{3}$ for trans- $\mathrm{Rh}\left(\mathrm{PR}_{3}\right)_{2}(\mathrm{CO}) \mathrm{Cl}$ and experimental values (with sample standard deviations) obtained from X-ray crystallography. Data from Table 2. PMes 3 excluded.

mechanics-based conformational search (with the Merck force field) of trans- $\mathrm{Rh}\left(\mathrm{PR}_{3}\right)_{2}(\mathrm{CO}) \mathrm{Cl}$ was performed using hybrid Monte Carlo methods; 2000 structures were generated and evaluated. The lowest-energy conformer thus found was refined by PM3(tm) optimization. The $\mathrm{S}_{4}{ }^{\prime}$ metric was calculated for each $\mathrm{PM} 3(\mathrm{tm})$-optimized trans- $\mathrm{Rh}\left(\mathrm{PR}_{3}\right)_{2}(\mathrm{CO}) \mathrm{Cl}$ using the recipe given above. These data are organized in Table 2. Figure 2 shows a comparison as a function of $\mathrm{R}$ of $\mathrm{S}_{4}{ }^{\prime}$ obtained from the PM3 $(\mathrm{tm})$ geometries and those obtained from CSD analysis of the general family of TM-PR 3 complexes. 
Inspection of Table 2 highlights several points that are particularly germane within the present context. First, the PM3(tm)-calculated, Rh-Vaska $S_{4}{ }^{\prime}$ tend to be higher than the crystallographic averages, Table 2, with the exception of $\mathrm{R}=$ $\mathrm{CF}_{3}$, for which only three examples are contained in the CSD. This suggests that the Rh "core" in these Vaska complexes is relatively sterically crowded, engendering a more compact $\mathrm{PR}_{3}$. Second, the sensitivity of $\mathrm{S}_{4}{ }^{\prime}$ is seen not only in the experimental standard deviations, Figure 2 and Table 2, but also in the range of average $\mathrm{S}_{4}{ }^{\prime}$ values (calculated or experimental) as a function of $\mathrm{R}$. Third, there is reasonable correspondence between $\mathrm{S}_{4}{ }^{\prime}$ specifically calculated for trans- $\mathrm{Rh}\left(\mathrm{PR}_{3}\right)_{2}(\mathrm{CO}) \mathrm{Cl}$ and those determined from $\mathrm{X}$-ray crystallography for a broader assortment of complexes. The greatest discrepancy is for $\mathrm{PMes}_{3}$, for which a relatively few experimental examples are known, with the remainder of the phosphines being within a standard deviation of the best-fit line, Figure 2. Thus, apart from the caveat that application of the $\mathrm{S}_{4}{ }^{\prime}$ protocol to extremely bulky phosphines should be done with care, this metric appears to be a reasonable steric parameter in the computational design and analysis of phosphine ligands and their transition metal complexes. We now turn our attention to calculable electronic parameters, to complement $\mathrm{S}_{4}{ }^{\prime}$.

3. Assessment of the Electronic Profile of Phosphines. The basic tenets of phosphine chemistry view such ligands as $\sigma$ donors and $\pi$ acceptors, although there remains discussion as to the orbitals utilized by the phosphine to accept electron density from the metal fragment, i.e., whether they are $\mathrm{P}-\mathrm{X}$ $\sigma^{*}$ and/or P $3 \mathrm{~d}$ orbitals. ${ }^{9}$ With respect to the bonding in $\mathrm{CO}$, there is more consensus; that is, donation of electron density from the metal fragment to the $\mathrm{CO}$ fragment will decrease $v(\mathrm{CO})$ due to population of the $\pi^{*}$ orbital of CO. Hence, it is expected that better phosphine $\sigma$ donors (or worse $\pi$ acceptors) will engender a lower $v(\mathrm{CO})$ stretch. Most attempts to quantify the electronic impact of a phosphine have focused on the effects that ligands have on $\mathrm{CO}$ stretching frequencies. For complexes with multiple $\mathrm{CO}$ ligands the highest energy or symmetric "breathing" mode is often used as the indicator.

Recently, it has been observed that computational chemistry can aid in the pursuit of electronic mapping by introduction of the computational electronic parameter $\left(\mathrm{CEP}^{12}\right)$ and the semiempirical electronic parameter $\left(\mathrm{SEP}^{14}\right)$. With these differing levels of theory, the CEP method utilizes ab initio techniques to model $\mathrm{Ni}(\mathrm{CO})_{3} \mathrm{~L}$ complexes. Density functional theory was used (the B3PW91 functional and a mixture of 6-31G(d,p) and 6-31G basis sets) to optimize and then calculate the highest $v(\mathrm{CO})$ symmetric stretch. The $\mathrm{CEP}^{12}$ method was followed by the SEP, ${ }^{14}$ in which the level of theory was semiempirical quantum mechanics so as to gain speed and access larger ligand sets. The $\mathrm{W}(\mathrm{CO})_{5} \mathrm{~L}, \mathrm{Mo}(\mathrm{CO})_{5} \mathrm{~L}$, and $\mathrm{CpRh}(\mathrm{CO}) \mathrm{L}$ complexes were targeted because previous research indicated that PM3(tm) is not reliable for nickel. ${ }^{18 a}$ The resulting optimized structures were then used in the calculation of the "breathing mode" or highest $\mathrm{A}_{1} v(\mathrm{CO})$ for $\mathrm{W}(\mathrm{CO})_{5} \mathrm{~L}$ and $\mathrm{Mo}(\mathrm{CO})_{5} \mathrm{~L}$ and $v(\mathrm{CO})$ for $\mathrm{CpRh}(\mathrm{CO}) \mathrm{L}$.

Previous research indicated the reliability of PM3(tm) for reproducing experimental trends in $v(\mathrm{CO})$ for different families of metal complexes $\left(\mathrm{Mo}(\mathrm{CO})_{5} \mathrm{~L}, \mathrm{~W}(\mathrm{CO})_{5} \mathrm{~L}\right.$, and $\mathrm{CpRh}(\mathrm{CO}) \mathrm{L}$ for $\mathrm{L}=$ phosphine). ${ }^{14}$ Additionally, the SEP method was competitive with the more expensive DFT methods, which are

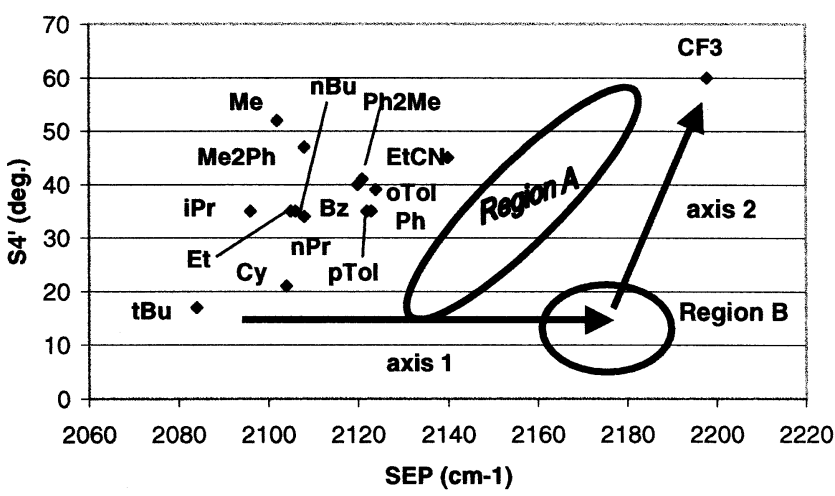

Figure 3. Calculated stereoelectronic map for phosphines derived from PM3(tm) calculations on trans- $\mathrm{Rh}\left(\mathrm{PR}_{3}\right)_{2}(\mathrm{CO}) \mathrm{Cl}$. Data from Table 2.

therefore limited to the study of small phosphine models such as $\mathrm{PF}_{3}$ and $\mathrm{PH}_{3}$. It should be noted that both types of calculations afford frequencies roughly $10 \%$ higher than experimental values.

For the same PM3(tm)-optimized geometries used to determine $\mathrm{S}_{4}{ }^{\prime}$, the IR spectrum was also calculated by numerical central differences to yield the SEP. Figure 3 shows a stereoelectronic plot for common phosphines (i.e., those that comprise the majority of phosphine ligands in the CSD) derived entirely from computation. Several points are of significance with respect to this computationally derived map. First, the semiempirical calculations reproduce (and more importantly quantify) chemically intuitive trends. The progression from $\mathrm{Me}$ to ${ }^{t} \mathrm{Bu}$ as the hydrogens of the former are successively replaced with methyl groups is plausible. This modification is expected to make the phosphine a better donor, and this is seen in the reduction in $v(\mathrm{CO})$, Figure 3. Second, the progression from $\mathrm{PMe}_{3}$ to $\mathrm{PMe}_{2} \mathrm{Ph}$ to $\mathrm{PMePh}_{2}$ to $\mathrm{PPh}_{3}$ shows the methyl/phenyl replacement to increase the steric bulk of the phosphine and at the same time result in a phosphine that is a poorer donor/better acceptor. Likewise, changes in position upon the map for $\mathrm{Me} \rightarrow \mathrm{CF}_{3}$ and $\mathrm{Et} \rightarrow$ EtCN substitution are all reasonable. Hence, the map shown in Figure 3 appears to be a viable route to the a priori study of novel phosphines, and hence the rational design of those that may possess novel stereoelectronic properties.

4. Application to Novel Phosphines. The utility of a computationally derived stereoelectronic map lies not in the mapping of well-studied phosphines such as $\mathrm{PMe}_{3}$ or $\mathrm{PPh}_{3}$, but rather in the application to novel or less researched phosphines. The power of the SEQM methodology used in generating Figure 3 is that it very clearly displays the presence of massive voids in the stereoelectronic map for common phosphines. The development, for example, of novel catalysts that contain a phosphine co-ligand would seem to be most profitable in these empty areas of the stereoelectronic map. The most noticeable voids in Figure 3 are large, electron-poor phosphines (region $\mathrm{B})$ and phosphines that lie along the axis from large, electronpoor $\rightarrow \mathrm{P}\left(\mathrm{CF}_{3}\right)_{3}$ (axis 2) and from ${ }^{t} \mathrm{Bu} \rightarrow$ large, electron-poor (axis 1). Additionally, phosphines that are median with respect to both electronic and donor properties are noticeably absent (region A, Figure 3), and thus constitute a worthy area for synthetic effort.

A series of novel phosphines and phosphites were targeted for further computational study to assess their location on the stereoelectronic map. Our working definition for a "novel" phosphine is one that (a) appears relatively infrequently in the CSD, (b) does not appear in the CSD, but is found in the 


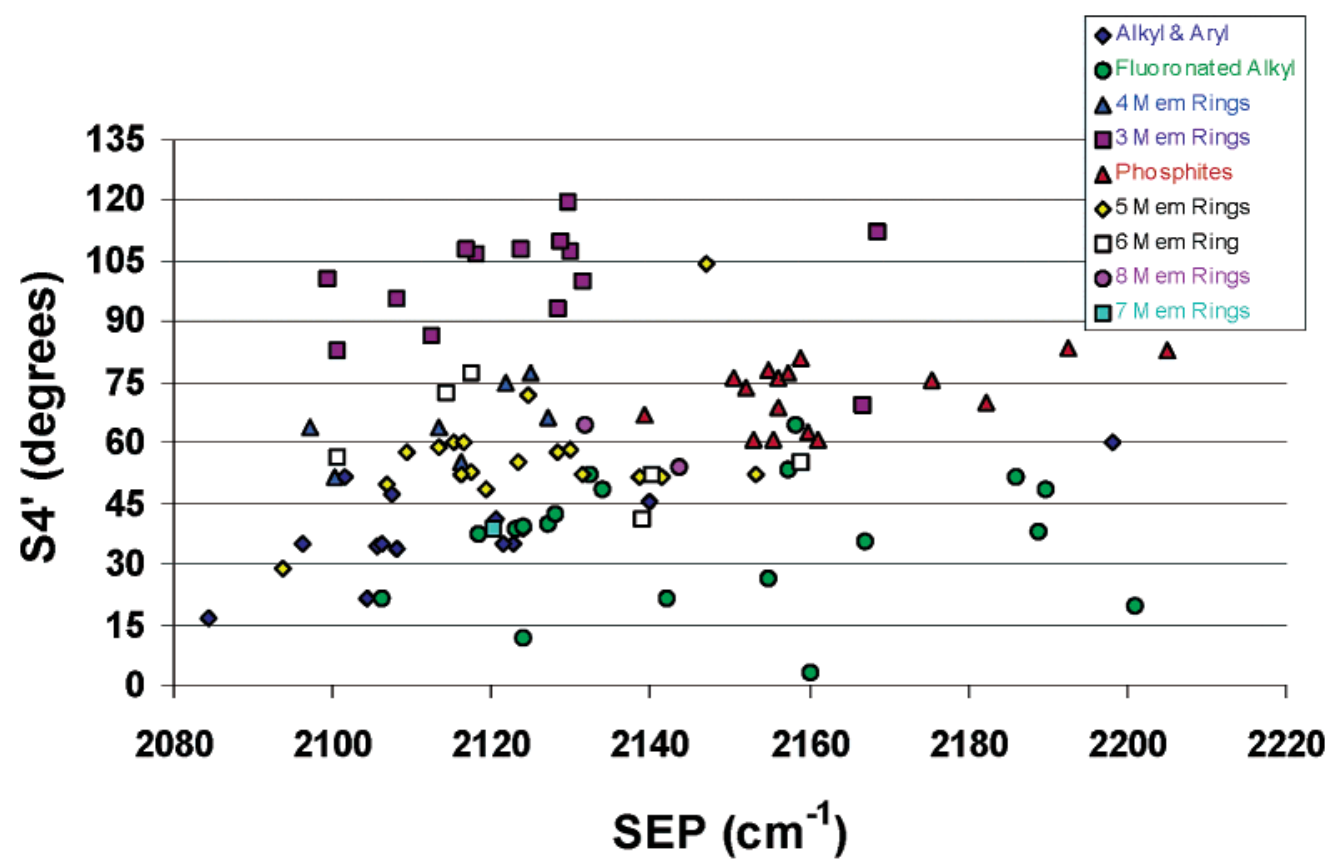

Figure 4. Expanded stereoelectronic plot with novel phosphines including phosphites, fluorinated alkyls/aryls, and ring phosphines.

Scheme 4

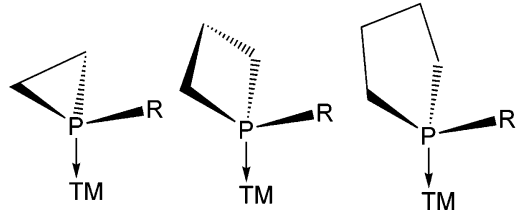

literature, or (c) is a simple derivative of the phosphines obtained from the first two criteria. Specific targets of interest include phosphites $\left(\mathrm{P}(\mathrm{OR})_{3}\right)$, fluorinated alkyl/aryl phosphines $\left(\mathrm{P}\left(\mathrm{R}_{\mathrm{f}}\right)_{3}\right)$, and phosphines in which the phosphorus is contained within a three-membered, four-membered, or larger ring (see Scheme 4 for examples).

A complete list of ligands studied and their $\mathrm{S}_{4}{ }^{\prime}$ and SEP values are given as Supporting Information. The calculated stereoelectronic data for the expanded phosphine set are presented in Figure 4.

It is clear from inspection of Figure 4 that the study of novel phosphines and phosphites has been successful in two regards. First, the novel phosphines have filled in the stereoelectronic gaps in the Tolman map in Figure 3. Second, the novel phosphines have expanded the limits of the original stereoelectronic map (i.e., phosphines that are outside the stereoelectronic limits established by the familiar phosphines used to generate Figure 3). A particularly interesting candidates for study is $\mathrm{P}\left(t-\mathrm{C}_{4} \mathrm{~F}_{9}\right)_{3}$, which fills a niche for a large, electron-poor phosphine. To our knowledge, no crystal structures of this ligand or its complexes have been reported, although Roddick et al. have made considerable progress in the synthesis of fluorinated phosphines. ${ }^{27}$ Further analysis of the properties of $\mathrm{P}\left(t-\mathrm{C}_{4} \mathrm{~F}_{9}\right)_{3}\left(\mathrm{~S}_{4}{ }^{\prime}=\right.$ $84^{\circ}$; SEP $=2193 \mathrm{~cm}^{-1}$ ) and the chemistry of its complexes would be of interest.

(27) (a) Houlis, J. F.; Roddick, D. M. J. Am. Chem. Soc. 1998, 120, 11020. (b) White, S.; Kalberer, E. W.; Bennett, B. L.; Roddick, D. M. Organometallics 2001, 20, 5731. (c) White, S.; Bennett, B. L.; Roddick, D. M. Organometallics 1999, 18, 2536. (d) Bennett, B. L.; Hoerter, J. M.; Houlis, J. F.; Roddick, D. M. Organometallics 2000, 19, 615. See also: Kampa, J. J.; Nail, J. W.; Lagow, R. J. Angew. Chem., Int. Ed. Engl. 1995, 34, 1241.
Another interesting class of ligands is phosphites, which are not as stereoelectronically diverse as phosphines. The oxygen atom insulates the phosphorus (and therefore the metal to which it is attached) from steric (since the $\mathrm{R}$ groups in $\mathrm{P}(\mathrm{OR})_{3}$ are now further from the $\mathrm{P}$ ) and electronic (due to the strong electronegativity of oxygen) effects arising from substituent modification. It must be noted that the accuracy of the PM3(tm) method for phosphites is not as good as for phosphines. For phosphite complexes, calculated MPO angles tend to be too high, while calculated OPO angles tend to be too low as compared to experiment. As a result, the phosphite contingent should be shifted down to make it more in line with alkyl/aryl phosphines. There is a paucity of crystallographic data for phosphites in relation to phosphines, much of it for the simple phosphines $\mathrm{P}(\mathrm{OMe})_{3}, \mathrm{P}(\mathrm{OEt})_{3}, \mathrm{P}\left(\mathrm{O}^{\mathrm{i} P r}\right)_{3}$, and $\mathrm{P}(\mathrm{OPh})_{3}$. Additionally, previous crystallographic and modeling studies by Caffery and Brown ${ }^{8}$ and Smith et al. ${ }^{25}$ show phosphites to be exceptionally conformationally flexible. For these reasons and the deficiencies noted above in the PM3(tm) modeling of phosphites, it is advisable to analyze phosphite data thus generated with considerable circumspection.

An especially interesting phosphite is $\mathrm{P}\left(\mathrm{OCF}_{3}\right)_{3}\left(\mathrm{~S}_{4}{ }^{\prime}=20^{\circ}\right.$; $\mathrm{SEP}=2201 \mathrm{~cm}^{-1}$ ) with the highest SEP among the phosphite ligands studied. No complexes of $\mathrm{P}\left(\mathrm{OCF}_{3}\right)_{3}$ have been reported in the CSD, although several references are found for it in the patent literature. ${ }^{28}$ This perfluorinated trimethyl phosphite is thus another interesting candidate for study to emerge from this work.

The cyclic phosphines (Scheme 4) comprise another set of interesting ligands. While the other previously discussed novel ligands fill the gaps in the original Tolman map, cyclic phosphines expand the stereoelectronic envelope of the phosphine family. This is especially so for the complexes in which the ligating phosphorus participates in a three-membered ring. The cyclic phosphine examples investigated are found in the

(28) (a) Yoshimura, S.; Nakajima, H.; Kamino, M. Jpn. Kokai Tokkyo Koho JP 2002231309, 2002. (b) Okamoto, T.; Yoshimura, S.; Fujitani, N. Jpn. Kokai Tokkyo Koho JP 2002025609, 2002. 
CSD, but only for a limited number of examples. Their calculated metrics match the experimental data to the same degree as for the other phosphines studied. The study shows the size of these phosphines to decrease steadily with decreasing size of the ring. The three-membered cyclic phosphines have extremely small stereoelectronic profiles. Derivatives that reach toward higher SEP values (i.e., are very electron withdrawing, perhaps through fluorination of the substituents) are worthy of computational and experimental study.

\section{Summary and Conclusions}

Several important points have come out of this research, the most important of which are summarized here.

(1) Analysis of the most common alkyl and aryl phosphines in experimental usage suggests that the complexes are quite similar stereoelectronically. Indeed, apart from $\mathrm{P}\left(\mathrm{CF}_{3}\right)_{3}$, it is interesting just how similar the commonly studied phosphines are. This highlights the exquisite sensitivity obtainable in chemical reactivity by varying the phosphine used in a catalytic process.

(2) A particularly noticeable gap in the Tolman map for common phosphines is observed for large, electron-poor phosphines. Several candidates meeting these criteria were identified, the most promising of which is $\mathrm{P}\left(t-\mathrm{C}_{4} \mathrm{~F}_{9}\right)$.

(3) Cyclic phosphines, which comprise a very small subset of the reported phosphines, have very interesting stereoelectronic properties, particularly those in which the ligating phosphorus is part of a three-membered ring.

(4) This research has demonstrated the utility of a semiempirical quantum mechanical protocol (as long as it is properly and rigorously calibrated) for developing a stereoelectronic map for phosphine ligands. In terms of steric properties, the symmetric deformation coordinate can be calculated with sufficient accuracy using PM3(tm) to allow good confidence in predictions of novel phosphines. A caveat in this regards is to be made for phosphites, whose accurate modeling is not commensurate with that of phosphines, perhaps due to the greater difficulty in describing the accuracy of $\mathrm{P}-\mathrm{O}$ versus $\mathrm{P}-\mathrm{C}$ bonds. For quantification of the electronic properties of phosphines, we analyzed changes in the $\mathrm{CO}$ stretching frequency upon changing the ancillary phosphine ligands.

Research is now in progress in our lab to investigate the extension of the methods described in this paper to the study of other important ligands in catalysis and the de novo design of inorganic/organometallic materials with tailored properties.

Acknowledgment. The majority of this research was carried out while the authors were at The University of Memphis. The authors would like to thank the National Science Foundation for funding this research through grant CHE-9983665. The research of M.D.T. and K.D.C. was funded through an NSFREU grant (CHE-9987775). The authors also gratefully acknowledge the Chemical Computing Group for their generous donation of the MOE program. N.W.H. acknowledges the Research Corporation for their support through grant C-3755.

Supporting Information Available: This material is available free of charge via the Internet at http://pubs.acs.org.

JA021254I 